\title{
Maternal Physiology
}

National Cancer Institute

\section{Source}

National Cancer Institute. Maternal Physiology. NCI Thesaurus. Code C16824.

Study of the physiologic, biochemical, and anatomic changes that occur during pregnancy. 